Sādhanā Vol. 28, Part 5, October 2003, pp. 925-932. ( $)$ Printed in India

\title{
Machining and metrology systems for free-form laser printer mirrors
}

\author{
D W DAVIS ${ }^{1}$, M WALTER $^{1}$, M TAKAHASHI $^{2}$ and T MASAKI $^{2}$ \\ ${ }^{1}$ Precitech Inc., 44, Blackbrook Road, Keene, New Hampshire 03431, USA \\ ${ }^{2}$ Matsushita Electric Industrial Co. Ltd., Matsuba-cho, Kadoma, Osaka 571-8502, \\ Japan \\ e-mail: \{ddavis, mwalter\}@Precitech.com
}

\begin{abstract}
A major challenge in optics is to make optical components like mirrors and lenses smaller and cheaper. This is achieved by designing optical components that have conformal or free-form shapes. A free-form optic is defined as one that is not symmetrical about any axis. These highly demanding requirements are met by single point diamond machining in rigid ultra precision machine tools.
\end{abstract}

Keywords. Free-form mirrors; diamond turning machines; form accuracy; surface finish.

\section{Introduction}

Nowhere is the drive to make things smaller and cheaper more prevalent than in consumer electronics. A major challenge is the cost-effective manufacture of free form shaped optical components for these systems. Free form optics are not symmetric about any axis of revolution and require multi-axis machining centres and metrology systems for their fabrication. These free form optics, machines, and metrology devices represent the next 'frontier' in ultra precision machine technology. Here we share with you one application for a free form optical surface.

Panasonic developed a free-form mirror which is used in the optical measuring system of a laser printer. The dimensions of the original mirror are $7 \mathrm{~mm}$ wide by $215 \mathrm{~mm}$ long, the focal distance is $180.2 \mathrm{~mm}$ and the scanning angle is $69.9^{\circ}$ the mould for this $215 \mathrm{~mm}$ mirror is shown in figure 1 on the left. To the right is the mould for an improved version of the same mirror which measures only $100 \mathrm{~mm}$.

\section{Design of existing optical scanning systems}

Until now, laser printer optical scanning systems utilized glass or plastic lenses and combined several lenses to form a system. As shown in figure 2, these systems based on conventional mirrors contain as many as 7-8 optical elements. The system on the left is a conventional system using only lenses, while the system on the right uses two aspheric mirrors and lenses. 


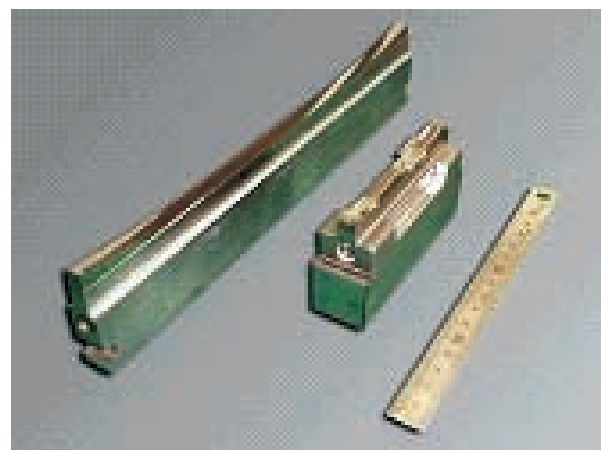

Figure 1. Electroless nickel, free form moulds.

By replacing these lenses in the optical system with a single free-form mirror, the number of components is reduced with corresponding benefits in cost reduction and size reduction. Further benefits include absence of chromatic aberration and the ability to select any wavelength of laser. Since the shorter wavelength laser results in spot size reduction, the preciseness of printing output is improved.

Conversely, a long wavelength laser can be used in a less expensive mass production printer with the same free-form optical scanning system (figure 3). The prior generation laser printer optical systems were designed and manufactured for the individual laser wavelength to be used because chromatic aberration was generated by the lens refractive index according to laser wavelength.
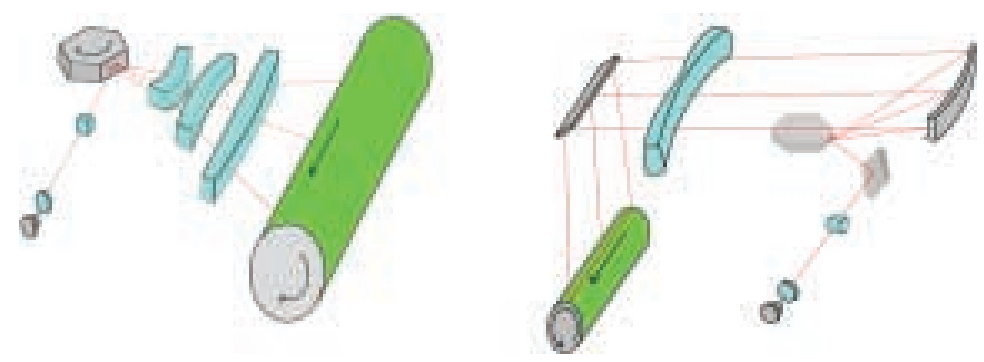

Figure 2. Conventional laser optical scanning systems.

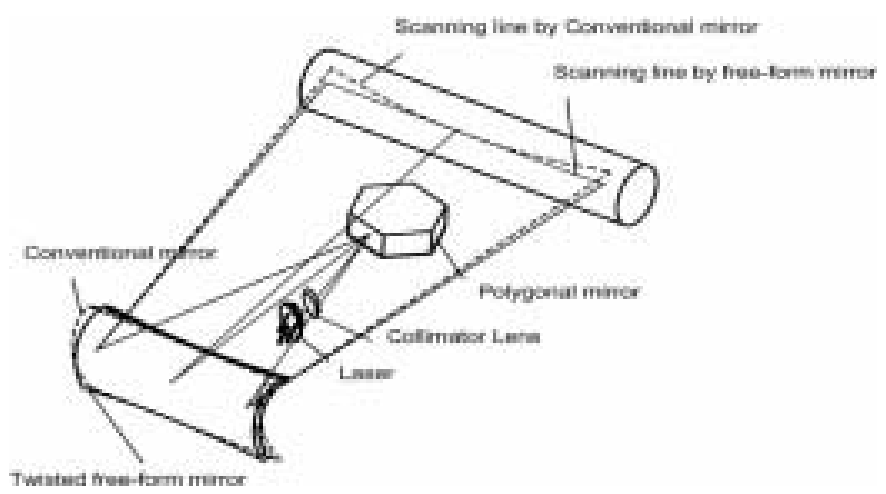

Figure 3. Free-form mirror-based optical scanning system. 


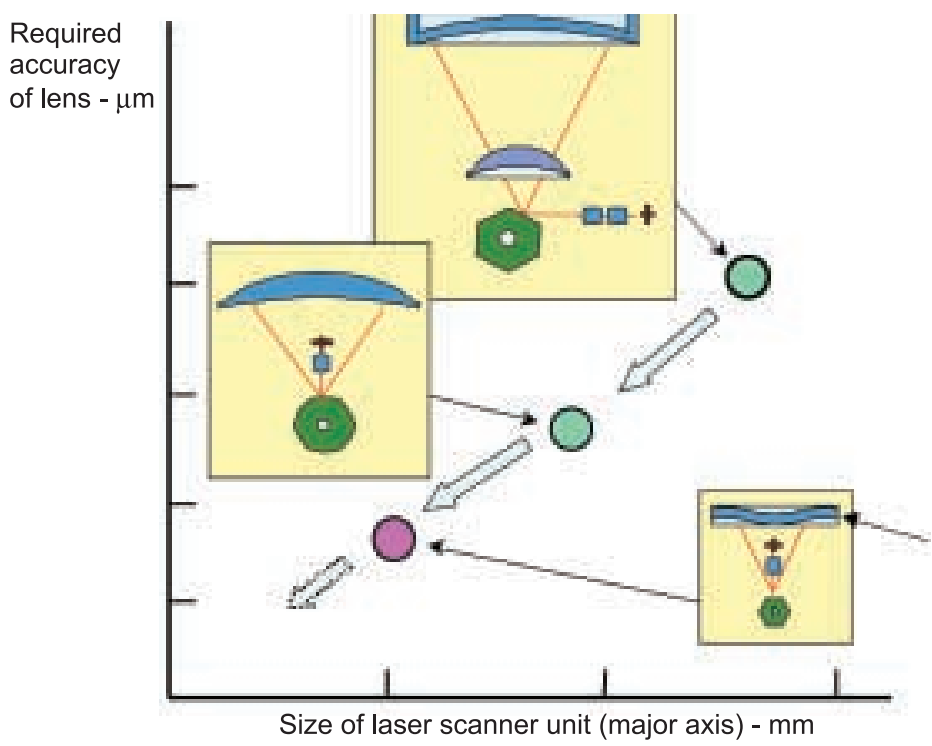

Figure 4. Transition of laser scanner unit.

The design objective in utilizing a free-form mirror has resulted in a corresponding reduction in component size and required accuracy, as can be seen in figure 4 . The component size was reduced while required accuracy of the lens improved from 0.4 micron to 0.15 micron with many current programmes requiring 0.1 micron or better.

\section{The machine, process and metrology technology}

The machine, process and metrology technology (figure 5) developed to fabricate the freeform optical mould together form a system for the manufacture of highly accurate free-form surfaces. Bridge style machines or column style machines are typical platforms currently utilized to manufacture non-rotationally symmetric free-form optics. What is important is that a minimum of 3 -axes of motion be provided. The Freeform ${ }^{\circledR} 4000$ manufactured for Matsushita shown in figure 6 is a bridge style hydrostatic slideway machine with air bearing spindle and ultra precision positioning. Linear motors for driving the slideways are important in order to provide smoother operation and better closed loop control of axes. The
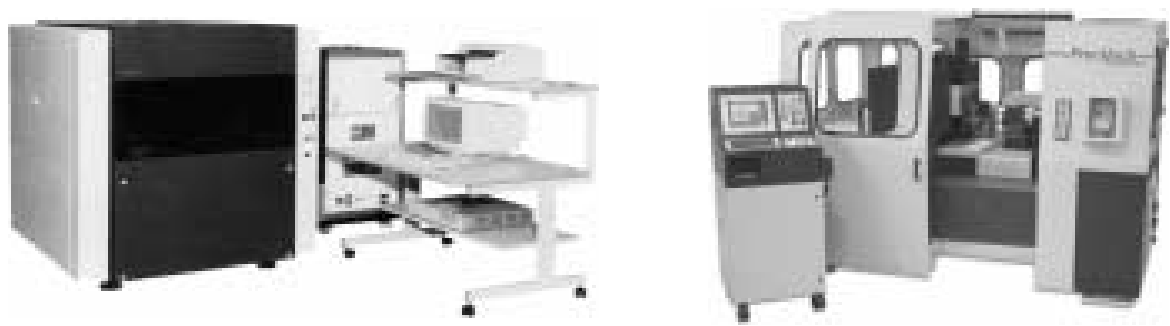

Figure 5. UA3P and Freeform ${ }^{\circledR} 4000$. 

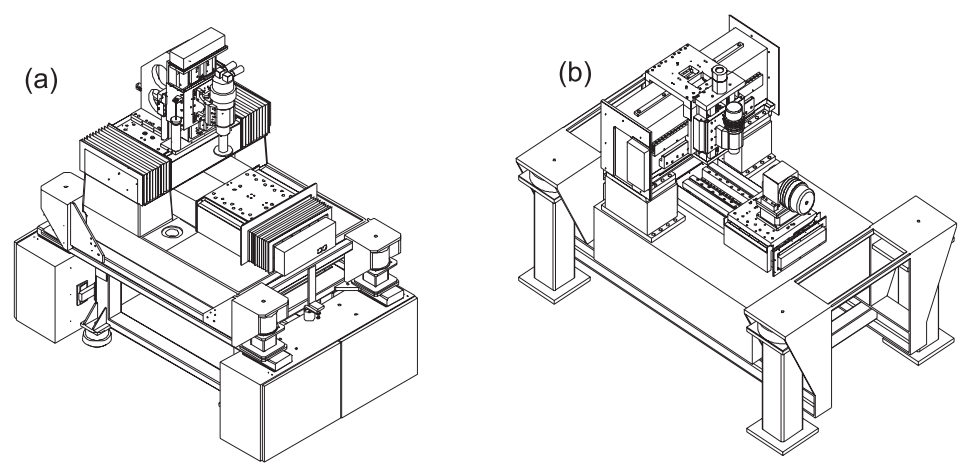

Figure 6. Freeform machine designs. (a) Freeform $3000^{\circledR}$-Column Style and (b) Freeform $4000^{\circledR}$-Bridge Style.

4000 machine utilizes a ballscrew vertical axis and linear motors on all other axes. Precitech also builds a multi-axis machine, Freeform ${ }^{\circledR} 3000$ shown also in figure 6 , utilizing a counterbalanced linear motor driven vertical axis. The Freeform ${ }^{\circledR} 4000$ machining system utilizes a fly cutting or diamond milling tool controlled to nanometric level (figure 7). Since mass production of these free-form mirrors is required, the components produced by the Freeform ${ }^{\circledR} 4000$ are moulds which are nickel $(\mathrm{Ni})$ coated on a copper $(\mathrm{Cu})$ substrate. The mirrors are injection moulded and then subsequently coated with aluminum (Al). It should be noted that the feed or scan direction is vertical in this picture. The machine is raster scanning or feeding in the vertical direction across the minor axis of the mould. The mould is clamped in a fixture on the slideway. The flycutter or raster milling tool is mounted on a vertical air bearing spindle while the mould is clamped in another air bearing spindle mounted horizontally. The horizontal spindle is clamped in position while the mould is being machined.

Matsushita developed the metrology equipment, UA3P, for evaluating the free-form mirror mould. The UA3P utilizes a non-contact atomic force microscope to measure and maintain measurement accuracy to $0.01 \mu \mathrm{m}$. Measurement range of the UA3P was improved to $400 \mathrm{~mm}$ in the X-Y directions. Analysis software for evaluating the free form optic was also developed. These products together form a system whereby measured errors are compensated for in the part program resulting in production of highly accurate non-rotationally symmetric surfaces. All repeatable errors such as tool form, machine positioning and straightness errors, programming errors as well as corrections from elsewhere in the process can be compensated for.

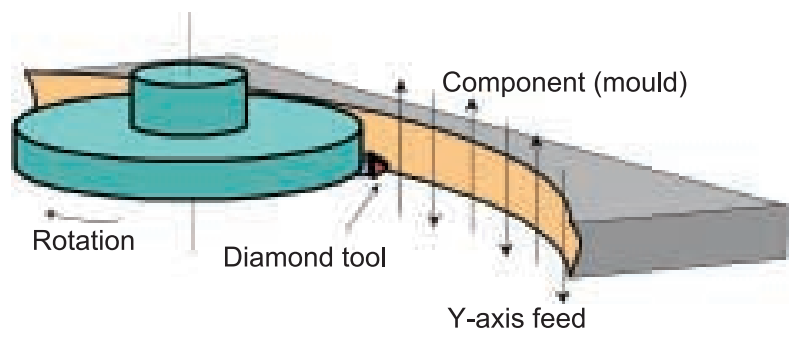

Figure 7. Raster flycutting process. 


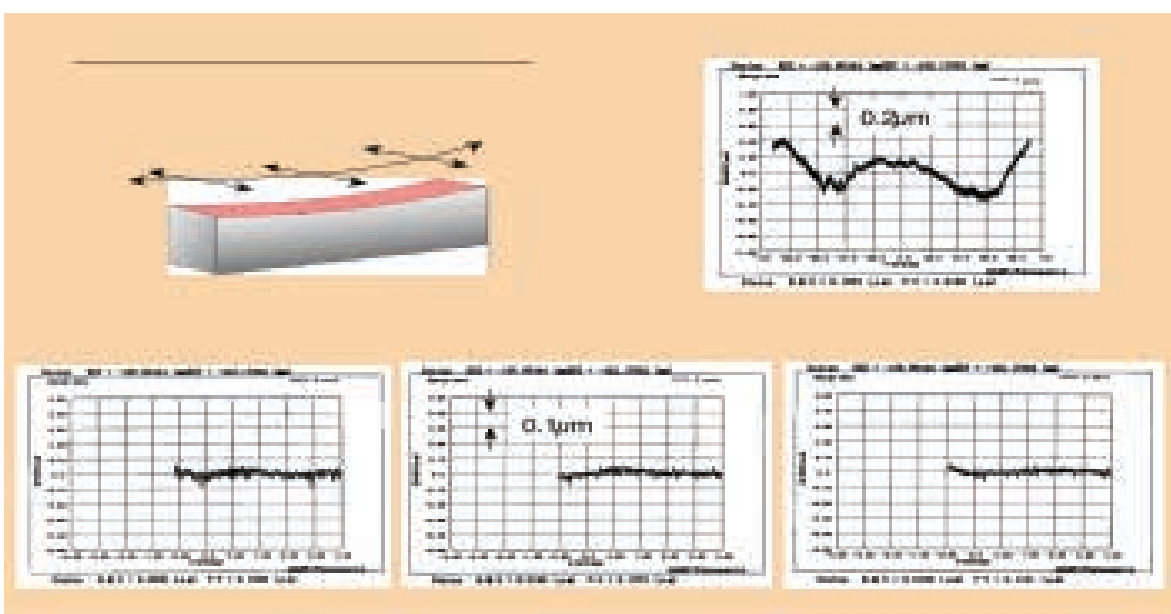

Figure 8. Form accuracy by $y$-axis scan.

\section{Cutting results when producing the free-form mould}

As shown in figure 8, form accuracy as measured on the Panasonic UA3P was as good as 0.1 micron $\mathrm{P}-\mathrm{V}$ measured across the minor axis and 0.8 micron $\mathrm{P}-\mathrm{V}$ measured along the major axis. The major axis has larger errors due to environmental thermal changes during the long part cutting cycle. The minor axis errors are more indicative of machine contouring ability. The minor axis is the most important for this application in terms of producing sharp character font resolution. Shown in figure 9 is the surface map of the component as measured on the Panasonic UA3P. Note that the $x$-axis and $y$-axis shown on this diagram is that of the UA3P and not of the machine. The part shown has an area of $200 \mathrm{~mm} \times 10 \mathrm{~mm}$ and form error of 0.8 micron as measured in the major axis. As measured on a WYKO interferometer and shown in figure 10 , the surface finish obtained in a $0.5 \mathrm{~mm} \times 0.5 \mathrm{~mm}$ area was $3.05 \mathrm{~nm}$ $\mathrm{Ra}$ and a line profile revealed $17.5 \mathrm{~nm} \mathrm{P}-\mathrm{V}$. Surface finish is controlled by the tool radius and

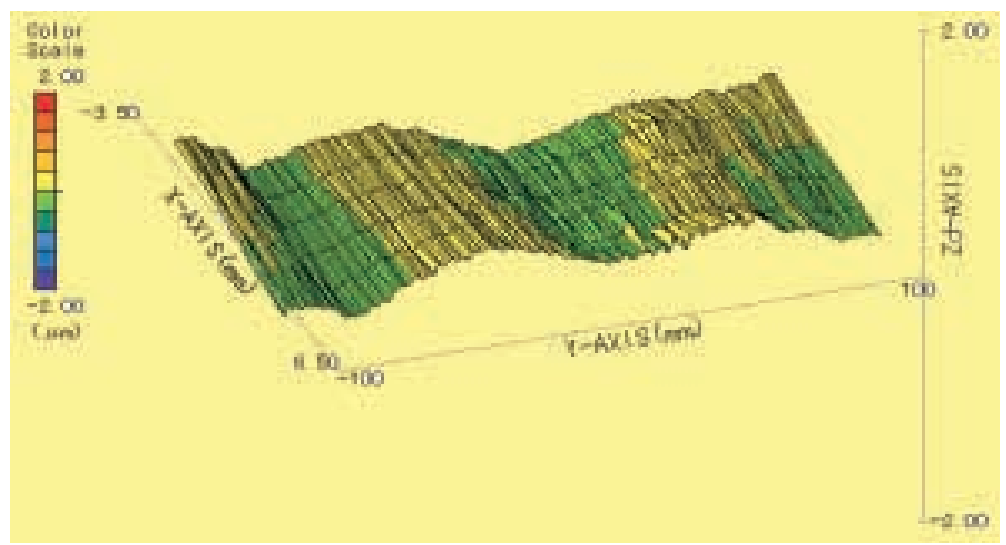

Figure 9. Machining accuracy of free-form mirror. 


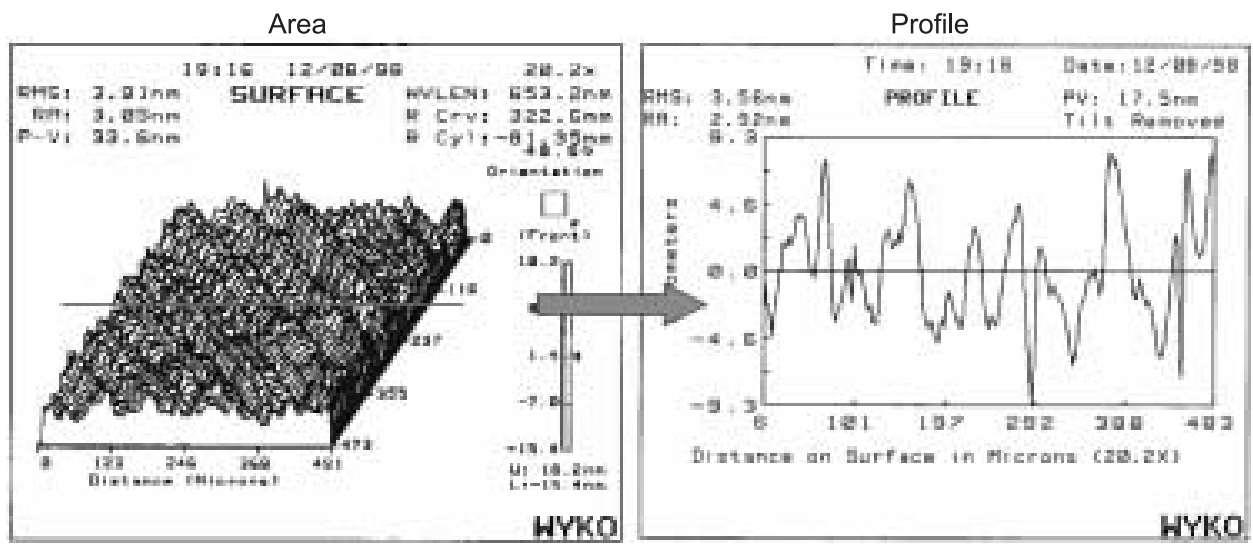

Figure 10. Surface finish in $y$-axis scan.

machine feed rates, creating a field of cusps or chip marks. These are not evident in these images, indicating that the feed rates were very slow. Surface finish was also checked after machining in the $x$-axis and $y$-axis directions. There was no visible difference as can be seen in these pictures at 2 different magnifications (figure 11).

In figure 12 the calculated surface finish is compared to the down cut or climb milling and to the up cut or conventional milling. At higher feed speeds the actual results from both milling processes are agreeable to calculated values. At slower feed speeds a greater difference exists with the calculated surface finish values. These differences could be a result of machine errors, material properties, tooling vibration or the interrupted cut of the flycutting/raster milling process. Tool life was better with climb milling.

The data in figure 13 is from a new product, the Freeform ${ }^{\circledR} 3000$, a column style machine introduced by Precitech. The form error is held better in the scan direction and thermal effects dominate the long term direction in a similar way to the Freeform ${ }^{\circledR} 4000$. Note that form error
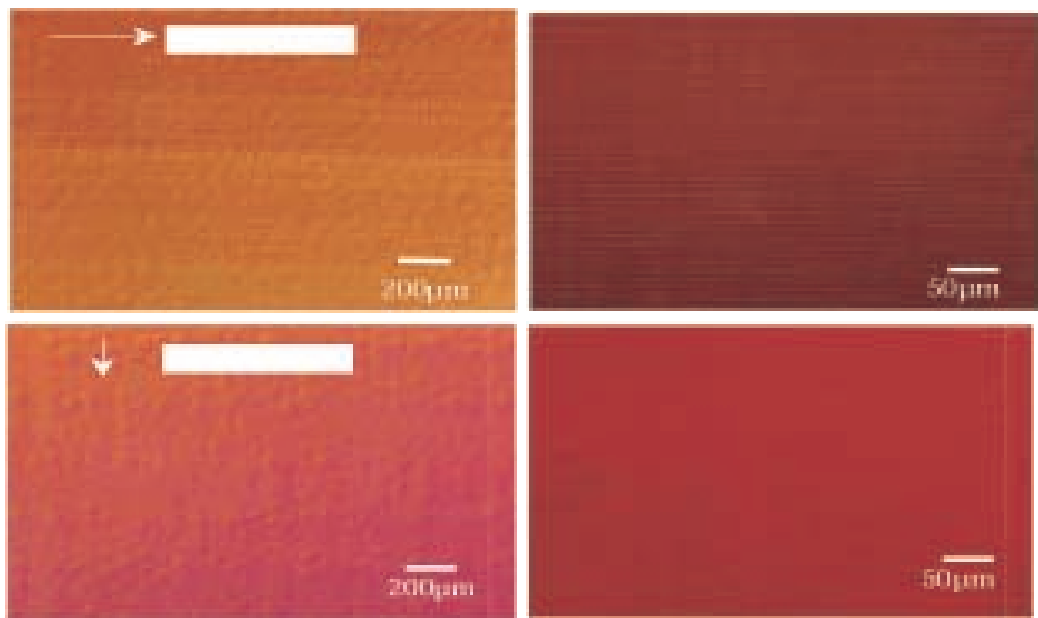

Figure 11. Surface finish by $y$-axis and $x$-axis scan. 


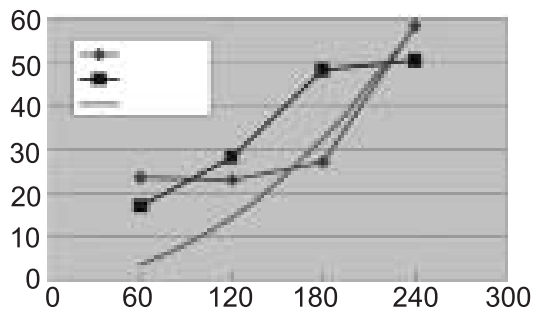

Figure 12. Relationship between feed rate and roughness.

is 0.128 micron $\mathrm{P}-\mathrm{V}$. The part machined was a test sphere which enabled measurement on a Zygo interferometer. The surface finish obtained for the same part is $18.5 \mathrm{~nm} \mathrm{Ra}$. The fly cutter tool and the expected cusping pattern to be generated on the surface of the workpiece are shown in figure 14.

Shown in table 1 are the major parameters that determine the surface finish, size of part program and cycle time. Given the inputs shown on the left hand column the expected results are shown in the right hand column. Note that the length of this particular part program which is 32 hours. Hence, temperature control is critical for minimizing form errors. Figure 15 shows recent temperature control data from a Freeform ${ }^{\circledR} 3000$. This data was taken while producing the earlier test sphere. Note the room temperature is fluctuating $1^{\circ} \mathrm{C}$. At the same time, the air supplied to the machining environment, the air supplied to the air bearing spindle and

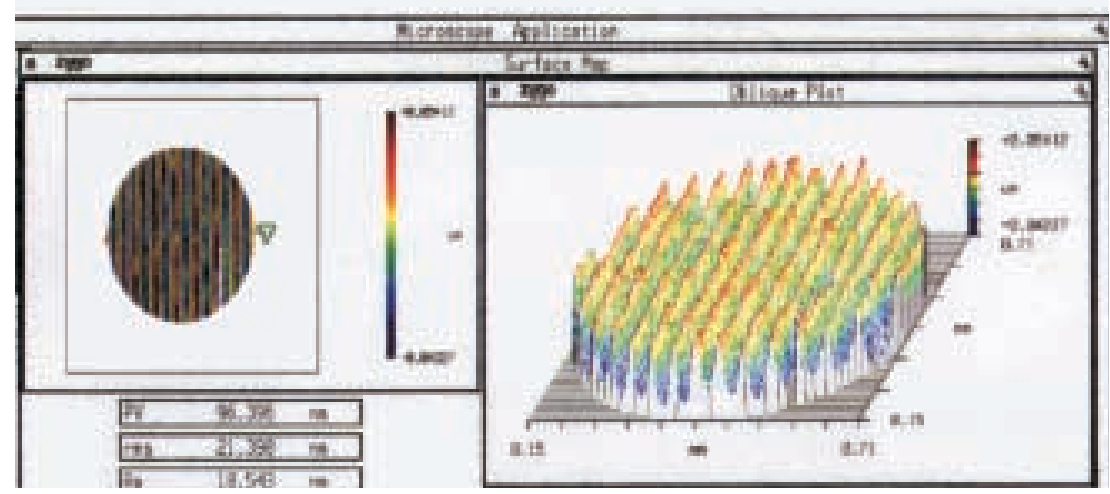

Figure 13. Freeform ${ }^{\circledR} 3000$ part cutting data.

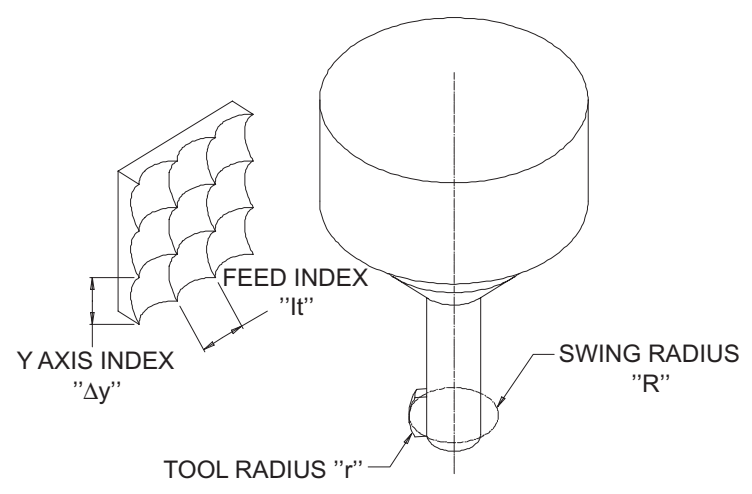

Figure 14. Machine configuration for generating cusping patterns. 
Table 1. Process inputs and results.

\begin{tabular}{ll}
\hline Input & \multicolumn{1}{c}{ Output } \\
\hline Spindle RPM 7100 & Scan cusp height $5 \mathrm{~nm}$ \\
Tool tip radius $5 \cdot 0 \mathrm{~mm}$ & Step cusp height $5 \mathrm{~nm}$ \\
Tool swing radius $5 \mathrm{~mm}$ & Machining time $32 \mathrm{hrs}$ \\
Scan width $100 \mathrm{~mm}$ & Program size $44 \mathrm{Mb}$ \\
Feed rate $100 \mathrm{mmpm}$ & Surface finish $2 \cdot 1 \mathrm{~nm}$ \\
Step width $25 \mathrm{~mm}$ & \\
Step $0 \cdot 014 \mathrm{~mm}$ & \\
\hline
\end{tabular}

the oil temperature supplied to the hydrostatic bearings is controlled within $0 \cdot 1^{\circ} \mathrm{C}$. This is achieved via a standard commercial temperature control unit. Key machine elements such as the spindle riser and flycutter were manufactured with Invar 36, a low coefficient of expansion nickel-based steel.

\section{Summary}

Optical systems are trending downward in size. Many smaller systems, such as laser printer optics, require free form surfaces for reflective and transmissive optical elements. The products featured in this report demonstrate the capability of producing and inspecting these free form surfaces. However, lengthy free form part cutting cycles require stable environment and machine temperature and due to the thermal changes during long part cutting cycles (30-40 hours), form accuracy in the scan/feed direction is significantly better than that in the step direction. This needs to be taken into consideration when programming the part.

Free form optics manufacturing is beginning a growth phase. Manufacturing and metrology equipment will continue to improve in performance and reduce in price, making the fabrication of these complex optical surfaces more cost-effective and prevalent in opto-electronic systems.

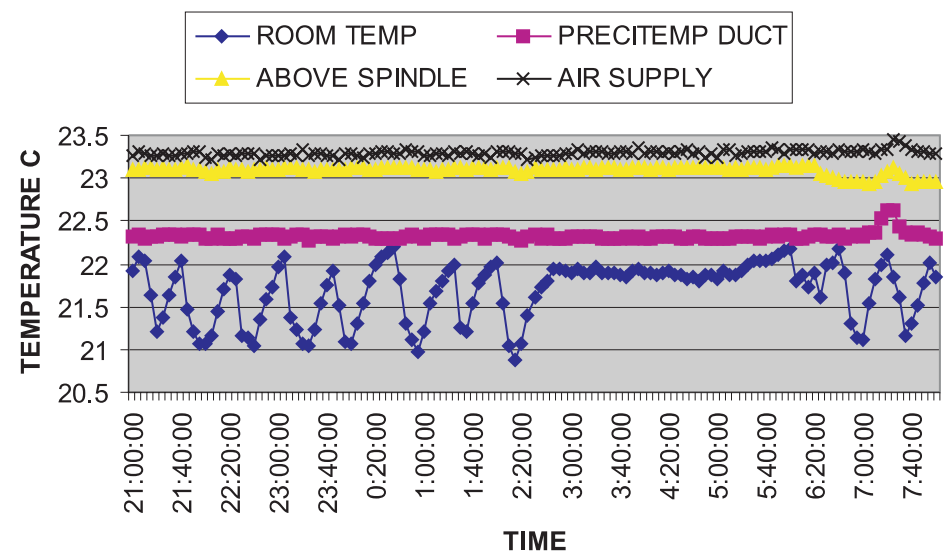

Figure 15. Temperature control. 